\title{
PERANAN JUST IN TIME METHOD \\ UNTUK PENINGKATAN PRODUKSI PERUSAHAAN
}

\author{
Willem \\ Email : willem@gmail.com \\ STIE Palangka Raya
}

\begin{abstract}
Market competition that is not only in national scope, transportation and communication tool progress have encouraged global competition. Technology advance plays an importance role in short goods circulation and increasing various types of produced goods. This research aims to determine (1). Any non value Added activities leading to non value added costs in the company (2). The extent of benefits and roles of Just In Time (JIT) Method in eliminating all non value activities or sources (3). To provide description on the importance of Just In Time application for the company in order to improve efficiency and productivity. This research used descriptive method, namely the research giving description on certain activity or project systematically, factually and appropriately and there are also some necessary analyses to overcome any faced problems and to find out any alternatives that can be used to anticipate various developments to be adjusted with the theory. Results of the research conclude that (1). Success in reducing or making efficient production cost can be seen in sale by savings (2). The figure is obtained from comparison of cost of goods before the JIT production system implementation with the cost of goods after the JIT production system implementation. (3) by reducing cost of goods, it is expected that the company can reduce its cost of sale, with the aim to add product competitiveness in the market and the company will obtain increased level of profits. (4) it can be seen that before the implementation of JIT production system, the company profit has increased after the implementation of JIT production system.
\end{abstract}

Keywords: Just In Time Method, Company Production Increase

PENDAHULUAN

Persaingan pasar yang tidak hanya dalam ruang lingkup nasional, berkembangnya transportasi dan alat komunikasi telah mendorong persaingan global. Kemajuan teknologi berperan penting dalam pendeknya perputaran barang dan semakin banyaknya jenis barang yang diproduksi.
Keberadaan

perusahaan perusahaan asing yang menawarkan produk dengan karakteristik khusus dengan berbiaya rendah menghasilkan kualitas tinggi telah menimbulkan tekanan berat bagi perusahaan lokal untuk meningkatkan kualitas dan jenis produk serta dalam waktu yang bersamaan mengurangi biaya produksi total. 
Tekanan kompetitif ini membuat banyak perusahaan meninggalkan model EQQ dan beralih kependekatan Jus In Time. Jus In Time mempunyai tujuan strategis yaitu meningkatkan pendapatan dan meningkatkan posisi perusahaan dalam persaingan. Tujuan ini dapat dicapai dengan pengendalian biaya, meningkatkan kinerja pengiriman dan peningkatan kualitas.

Just In Time menawarkan peningkatan efisiensi biaya dan fleksibilitas dalam menjawab permintaan keuntungan perusahaan menurun sebagai akibat dari tingginya biaya dan menyusutnya pangsa pasar. Pemborosan akan berdampak pada kualitas dan penyerahan barang Operasi yang tidak bermanfaat mempunyai kecendrungan memperburuk kualitas, yaitu defect, scrap dan rework. Proses yang tidak bermanafaat dalam rangkaian bisnis juga akan memperbesar leadtimes, akibatnya penyerahan menjadi terlambat . Kualitas dan penyerahan buruk akan berakibat menurunnya tingkat kepuasan konsumen .

Pengurangan pemborosan adalah pendorong utama Just In Time, hal ini juga merupakan tujuan utama dari semua perusahaan, baikitu penggiuna Just In Time atau bukan. Just In Time lebih sekedar dari sistem manajemen persediaan . Barang persediaa yang meliputi sumber daya seperti dana, ruang dan tenaga kerja di pandang sebagai suatu pemborosan.

Didalamnya tersembunyi efisiensi dalam produksi dan meningkatnya kompleksitas dari sistem informasi dari suatu perusahaan. Meski Just In Time lebih sekedar memusatkn perhatian pada manajemen persediaan, namun pengendalian persediaan ini sangat penting manfaatnya. judul Penelitian ini adalah "Peranan Just In Time Method Untuk Peningkatan Produksi Produk”.

Tujuan penelitian yang dilakukan adalah (1). Untuk mengetahui macammacam pemborosan (non value Added activity) yang menimbulkan suatu biaya yang tidak bernilai tambah pada perusahaan (2). Untuk mengidentifikasi sejauh mana manfaat dan peranan Just In Time (JIT) Method dalam mengeliminasi semua aktivitas atau sumber-sumber yang tidak bernilai tambah (3). Untuk memberi gambaran tentang pentingnya penerapan Just In Time bagi perusahaan guna meningkatkan efisiensi dan produktivitas 


\section{TINJAUAN PUSTAKA}

\section{Pengertian Just In Time}

Pengertian Just In Time adalah tepat pada waktunya. Istilah tepat tepat waktunya ini digunakan untuk menunjukan bahwa sebuah proses bisa mendapatkan tanggapan langsung terhadap permintaan tanpa perlu menyediakan stock berlebihan baik dalam harapan bahwa permintaan ini akan datang maupun sebagai akibat ketidak efisienan dalam prosesnya. Tjiptono dan Diana (1996) “Just In Time merupakan filosofi manufakturan yang memeliki implikasi penting dalam manajemen biaya.

Ide dasar JIT sangat sederhana, yaitu berproduksi hanya apabila ada permintaan (Pull System) atau dengan kata lain hanya memproduksi sesuatu yang diminta pada saat diminta., dan hanya sebesar kuntitas yang diminta.

Mas'ud Machfoedz (1996) memberikan pengertian Just In Time sebagai berikut : "Filosofi peningkatan kualitas produk dan efisiensi biaya produksi melalui volume persediaan sampai batas minimal.“ Sedangkan Taichi Ohno (1995) memberikan pengertian Just In Time berarti bahwa dalam suatu rangkaian proses produksi, suku cadang yang diperlukan untuk perakitan tiba pada ujung lini rakit pada waktu yang diperlukan hanya dalam jumlah diperlukan. Perusahaan yang menerapkan sistem ini pada seluruh lini produksi dapat mendekati sediaan nol.

Pengertian lain dikemukakan oleh Masaaki Imai (1998) “Just In Time adalh sistem produksi yang dirancang untuk mendapatkan kualitas , biaya dan waktu penyerahan yang sebaik mungkin ,dengan menghapuskan semua jenis pemborosan yang terdapat diddalam proses internal sehingga mampu menyerahkan produk sesuai dengan kehendak konsumen secara tepat waktu. Memperhatikan beberapa pendapat diatas, maka dapat kesimpulan bahwa Just In Time adalah suatu sistem manufakturan maju dalam usahanya untuk meningkatkan suatu kualitas produk dan efisiensi biaya produksi.

\section{Aspek Just In Time}

Menurut Tjitono dan Diana (1996) Terdapat empat aspek pokok dalam konsep Just In Time, diantaranya :

a. Semua aktivitas yang bernilai tambah terhadap produk atau jasa harus dieliminasi. Aktivitas yang tidak bernilai tambah meningkat biaya (pemakaian sumber-sumber ekonomi) yang tidak perlu, misalnya 
persediaan sedapat mungkin nol (Zero Inventory).

b. Adanya komitmen untuk selalu meningkatkan mutu yang lebih tinggi .Komitmen ini diperlukan agar dapat mengerjakan sesuatu dengan benar pada saat pertama sehingga produk rusak atau cacat sedapat mungkin nol , tidak memerlukan waktu dan biaya untuk mengerjakan kembali produk cacat, dan kepuasan pembeli dapat meningkat.

c. Selalu diupayakan penyempurnaan yang berkesinambungan (continous inprovement) dalam meningkakan efisiensi kegiatan .Komitmen ini merupakan salah satu upaya agar dapat dihasilkan produk yang bermutu tinggi dan berbiaya rendah .

d. Menekankan pada penyederhanaan aktivitas dan meningktkan pemahaman terhadap aktivitas yang bernilai tambah. Komitmen ini sekaligus dapat mmbantu mengidentifikasian aktivitas yang tidak bernilai tambah sehingga aktivitas ini dapat dieliminasi.

\section{Cii-ciri Just In Time}

Taichi Ohno (1995) Just In Time berarti bahwa dalam suatu rangkaian proses produksi, suku cadang yang diperlukan untuk perakitan tiba pada ujung lini rakit pada waktu yang diperlukan hanya dalam jumlah diperlukan. Ciri Just in time meliputi :

a. Persediaan sebagai musuh sebab persediaan bersifat tidak bernilai tambah,.Aktivitas yang tidak bernilai tambah adalah salah satu hal yang oleh pelanggan dirasa tidak menambah utilitas atau manfaat suatu produk.

b. Perhatian ditujukan pada pengurangan manufacturing lead time, yaitu waktu sejak sebuah pesanan siapdimulai pad lini produksi sampai saat menjadi suatu produk jadi. Mengurangi lead time memungkinkan perusahaan untuk bereaksi lebih baik atas setiap titik waktu

c. Aktivitas produksi disederhanakan. Aktivitas yang tidak bernilai tambah disoroti dan kemudian dikurangi atau dihilangkan.

d. Produksi di hentikan jika ditentukan ada part yang tidak atau rusak, penekanan diberikan untuk mengurangi kerusakan secapat mungkin .Ini mengakibatkan lebih sedikit unit yang dikerjakan ulang atau barang rusak .Sebaliknya, dalam banyak sistem produksi tradisional part ekstra dan sub assemblies 
diperthankan pada stasiun kerja untuk mengantisipasi kekurangan atau kemacetan produksi.

\section{Tujuan Just In Time}

Supriyono (1994) memberikan dua tujuan strategi Just In Time yaitu (1) Meningkatkan laba (2) Memperbaiki posisi persaingan perusahaan. Menurut Tjitono dan Diana (1996) tujuan Just In Time adalah meningkatkan laba dan posisi persaingan perusahaan yang dicapai melalui usaha pengendalian biaya, peningkatan kualitas, serta perbaikan kinerja pengiriman."

Sedangkan David Hutchins (1997) memberikan tujuan Just In Time sebagai beriukut (1) Meminimumkan penyimpanan stock (2) Menurunkan biaya (3) Meningkatkan pangsa pasar (4) Mengalahkan pesaing

Mengendalikan sumber daya setiap orang yang digaji menuju pembuatan perusahaa yang terbaik dalam bisnisnya.

\section{Peranan Just In Time}

Meski Just In Time seringkali disebut sebagai sistem produksi tanpa stock, namun sesungguhnya semua itu harus dipertimbangkan berdasarkan praktek. Pertama, orang dapat membayangkan adanya mata rantai yang tak tampak dari konsumen dengan jalur proses produksi. Waktu tempuh produksi yang singka memungkinkan pengerahan produksi dimulai setelah pesanan diterima, sementara itu petugas dapat selalu bekerja dengan fokus konsumen yang jelas, seolah-olah konsumen sedang menunggu selesainya produk yang dipesannya diruang tamu.

Kedua, sistem ini memungkinkan fleksibelitas yang tinggi dalam memenuhi kehendak dan permintaan konsumen . Dengan menggunkan sarana kanban, persediaan produk model populer langsung dapat segera diganti begitu produkterjual. Hal ini tentu saja mengurangi jumlah persaediaan.

Ketiga, sistem produksi ini dapat segera menaggapi ketidak wajaran yang terjadi dijalur produksi. Bila ada produk gagal atau caat, seluruh jalur dihentikan untuk perbaikan, karena tak akan ada lagi kesempatan untuk mengganti produkcacat tersebut. Dengan kata lain , manajemen menangani secara serius semua masalah yang muncul dijalur produksi denghan menghentikan jalur, sampai akhirnya produksi betul-betul terbebas dari berbagai masalah. Semua masalah kualitas, gagal fungsi peralatan, maupun kesalahan dari manusia harus 
ditangani dan ditanggulangi agar jalur berjalan.

Keempat , sistem produksi ini membantu perusahaan dalam meramalkan kecendrungan pasar secara lebih tepat dan akurat, dan halkelima JIT membuka kemungkinan penjadwalan produksi secara fleksibel.

\section{Manfaat Just In Time}

Adapun manfaat Just In Time menurut Amin Widjaya Tunggal (1995) adalah sebagai berikut :

a. Praktek JIT mengurangi tingkat persediaan yang berarti investasi yang lebih rendah dari persediaan .Karena sistem JIT hanya mensyaratkan kuantitas yang terkecildari material yang diperlukan segera, JIT mengurangi tingkat persediaan secara keseluruhan.

b. Rencana pembelian dibawah JIT mensyaratkan suatu waktu tenggang pengiriman (delivery lead time )yang secara signifikan lebih pendek , keandalan waktu tenggang sangat besar diperbaiki.

c. Waktu tenggang dan penyiapan mesin serta peralatan meningkatkan kelenturan penjadwalan. Waktu tenggang komulatif yang mencakup baik waktu tenggang dan waktu produksi dikurangi.. d. Tingkat mutu yang diperbaiki telah dilporkan oleh banyak perusahaan.Apabila kuantitas pesanan kecil, sumber masalah mutu dapat dengan cepat diidentifikasi dan dan dapat diperbaiki segera.

e. Biaya material yang di beli dapt dikurangi dikurangi melalui analisis nilai yang lebih ekstensif dan kegiatan pengembangan pemasok yng kooperatif.

f. Manfaat keuangan lain, yaitu : (1) Investasi yang lebih rendah dalam persediaan (2)Mengurangi biaya dan menangani persediaan Mengurangi resiko keuangan persediaan (4) Investasi yang lebih rendah dalam ruangpabrik untuk perse3diaan dan produksi Pengurangan dalam total pabrikasi.

\section{Hubungan Just In Time Terhadap Non Value Added Activity}

Waktu merupakan elemen penting Just In Time, karena itu sisitem akuntansi biaya dari JIT mengukur waktu yang dibutuhkan dalam kegiatan operasi perusahaan. Pengukuran waktu itu penting untuk penjadwalan aktivitas produksi dalam rangka menghindari adanya bottleneck (terjadinya tenggang waktu karena keterlambatan prosews setelah proses sebelumnya selesai) dan 
memastikan bahwa pekerhjaan tepat pada waktunya.

Perubahan kalkulasi biaya produksi yang disebabkan filosofi JIT dapat dihubungkan dengn konsep dari seluruh operasi .Teknik kalkulasi biaya produksi dipengaruhi oleh pengeliminasi komponen yang tidak bernilai tambah yang mengakibbatkan pemborosan . Dimana penyederhanaan juga merupakan tujuan dari JIT.

Untuk memahami pendekatn JIT dalam kalkulasi biaya produk , menurut Amin Widjaya Tunggal (1991:91) perlu menguhubungkan elemen waktu dsari proses produksi trdisional, sebagai berikut :

1) Waktu pemrosesan (processing time ) yaitu jumlah waktu actual suatu produk dikerjakan .

2) Waktu inspeksi (inspection time) yaitu waktu yang digunakan baik untuk menemukan produk yang rusak atau mengerjakan ulang unit yang rusak.

3) Waktu pindah (moving time) yaitu waktu yang digunakan untuk memindahkan produk dari suatu operasi atau departemen.

4) Waktu tunggu (wait time0 yaitu waktu yang dihabiskan suatu produk menunggu untuk dikerjakan pada waktu mereka tiba pada operasi yang berikutnya.

5) Waktu penyimpanan (storage time) yaitu waktu suatu produk , baikdalam gudang penyimpanan bahan baku, persediaan barang setengah jadi atau persedian barang jadi menunggu untuk di jual atau dikitrim.

Secara luas pengukuran efisiensi dari sistem Just In Time di kenal MCE (Manufacturing Cycle Efficiency) yaitu MCE $=\frac{\text { Value Added Time }}{\text { Throughput Time }}$

Throughput time adalah interval waktu dimulainyaproses produksi sampai produksi selesai dan dikirim kepada pelanggan , Dalam throughput time dibagi menjadi suatu aktivitas yitu value added activities dan non value added activities. Throughput time mempunyai empat komponen yaitu : processing time, inspection time, moving time, dan waiting/storage time.

\section{METODE PENELITIAN}

Penelitian adalah jenis penelitian studi kasus yang merupakan penelitian untuk mengetahui keadaan dan masalah obyek yang diteliti secara mendalam, 
faktual dan komperhensif dengan menggunakan metode deskriftif.

Variabel penelitian yang digunakan adalah (a). Move Time yaitu waktu yang di perlukan untuk memindahkan produk dari satu departemen ke departemen berikutnya. (b)Waiting Time yaitu waktu dimana produk berada dalam suatu departemen sebelum diproses. (c). Inspection Time yaitu waktu yang diperlukan untuk menginspeksi produk untuk menjamin bahwa produk telah sesuai dengan standar produksi.

Dalam penelitian ini akan di gunakan 2 metode analisa yaitu (a) Analis kualitatif merupakan suatu analisa yang didasarkan atas teori-teori dan pendapat dari para ahli terhadap pembahasan yang tyelah dilakukan sehingga dihasilkan suatu kesimpulan. (b). Analisa kuantitatif yaitu merupakan suatu cara untuk menganalisa data yang bersifat kuantitatif yang pada umumnya berbentuk suatu model matematis maupun tabel atau juga bias berbentuk alat ukur tertentu dan analisa dengan menggunakan alat analisa yang disediakan.

Adapun alat analisa yang digunakan adalah Analisa Manufacturing
Efficiency (MCE) yang dihitung dengan rumus :

$$
\text { MCE }=\frac{\text { Value Added Time }}{\text { Throughtput Time }}
$$

\section{HASIL PENELITIAN DAN \\ PEMAHASAN}

\section{Hasil Penelitian}

\subsection{Deskripsi Variabel}

Pada deskripsi variabel ini akan dijelaskan mengenai kerangka konsep dalam penerapan konsep dalam Just In Time Method dalam upaya mengeliminasi Non Value Added Activity pada Perusahaan. Adapun variabel-variabel yang akan diteliti berdasarkan konsep diatas adalah (a). Move Time Yaitu waktu yang diperlukan untuk memindahkan produk dari suatu departemen ke departemen berikutnya (b). Waiting Time Yaitu waktu dimana produk berada dalam suatu departemen sebelum diproses (c). Inspection Time Yaitu waktu yang di perlukan untuk menginspeksi produk untuk menjamin bahwa produk telah sesuai dengan standar produksi. 


\subsection{Jam kerja normal}

Adapun data jam kerja normal perusahaan Tahun 2017 adalah sebagai berikut.

Tabel 1

Data jam kerja normal perusahaan

Tahun 2017

\begin{tabular}{|c|c|c|}
\hline Bulan & $\begin{array}{c}\text { Hari } \\
\text { Kerja } \\
\text { (hari) }\end{array}$ & $\begin{array}{c}\text { Jam Kerja } \\
\text { Normal (jam) }\end{array}$ \\
\hline Januari & 26 & 176 \\
\hline Februari & 23 & 155 \\
\hline Maret & 25 & 167,5 \\
\hline April & 24 & 162 \\
\hline Mei & 25 & 167,5 \\
\hline Juni & 25 & 169 \\
\hline Juli & 26 & 176 \\
\hline Agustus & 26 & 176 \\
\hline September & 26 & 176 \\
\hline Oktober & 27 & 183 \\
\hline Nopember & 24 & 160,5 \\
\hline Desember & 26 & 176 \\
\hline Total & 303 & $2.044,5$ \\
\hline
\end{tabular}

Sumber : Perusahaan diolah, 2017

\subsection{Hasil Produksi}

Tabel 2

Hasil Produksi Tahun 2017

\begin{tabular}{|l|c|c|c|}
\hline Bulan & $\begin{array}{c}\text { Hari } \\
\text { Kerja } \\
\text { (hari) }\end{array}$ & $\begin{array}{l}\text { Jam } \\
\text { Kerja } \\
\text { Normal } \\
\text { (jam) }\end{array}$ & $\begin{array}{l}\text { Produksi } \\
\text { (Potong) }\end{array}$ \\
\hline Januari & 26 & 176 & 3.100 \\
\hline Februari & 23 & 155 & 3.250 \\
\hline Maret & 25 & 167,5 & 3.475 \\
\hline April & 24 & 162 & 3.850 \\
\hline Mei & 25 & 167,5 & 3.750 \\
\hline Juni & 25 & 169 & 3.900 \\
\hline Juli & 26 & 176 & 4.000 \\
\hline Agustus & 26 & 176 & 3.425 \\
\hline September & 26 & 176 & 3.400 \\
\hline Oktober & 27 & 183 & 3.800 \\
\hline Nopember & 24 & 160,5 & 3.900 \\
\hline
\end{tabular}

\begin{tabular}{|c|c|c|c|}
\hline Desember & 26 & 176 & 4.050 \\
\hline Total & 303 & $2.044,5$ & 43.900 \\
\hline
\end{tabular}

Sumber : Perusahaan diolah, 2018

\subsection{Jam kerja sesungguhnya}

Selain bekerja pada jam normal, perusahaan juga menambah jam lembur bagi karyawannya . Adapun jam lembur dan jam kerja sesungguhnya per bulan selama tahun 2017 adalah sebagai berikut :

Tabel 3

Jam Kerja Sesungguhnya Tahun 2017

\begin{tabular}{|l|c|c|c|}
\hline Bulan & $\begin{array}{c}\text { Hari } \\
\text { Kerja } \\
\text { Normal }\end{array}$ & $\begin{array}{l}\text { Jam } \\
\text { Lembur }\end{array}$ & $\begin{array}{l}\text { Jam } \\
\text { Kerja } \\
\text { Sesung- } \\
\text { guhnya }\end{array}$ \\
\hline Januari & 176 & 20 & 196 \\
\hline Februari & 155 & 17 & 172 \\
\hline Maret & 167,5 & 30 & 197,5 \\
\hline April & 162 & 30 & 192 \\
\hline Mei & 167,5 & 29 & 196,5 \\
\hline Juni & 169 & 25 & 194 \\
\hline Juli & 176 & 28 & 204 \\
\hline Agustus & 176 & 22 & 198 \\
\hline September & 176 & 25 & 201 \\
\hline Oktober & 183 & 20 & 203 \\
\hline Nopember & 160,5 & 26 & 186,5 \\
\hline Desember & 176 & 26 & 202 \\
\hline \multicolumn{1}{|c|}{ Total } & $2.044,5$ & 298 & $2,342,5$ \\
\hline
\end{tabular}

Sumber : Perusahaan diolah, 2018

\subsection{Biaya Produksi}

Dalam melakukan kegiatan produksinya, Untuk penulisan ini diambil produksi untuk tahun terakhir yaitu tahun 2017. 
Tabel 4

Biaya Produksi

\begin{tabular}{|l|r|}
\hline \multicolumn{1}{|c|}{ Jenis Biaya } & Biaya \\
\hline $\begin{array}{l}\text { Pemakaian } \\
\text { bahan baku }\end{array}$ & 575.085 .850 \\
\hline $\begin{array}{l}\text { Biaya tenaga } \\
\text { kerja langsung }\end{array}$ & 416.210 .000 \\
\hline $\begin{array}{l}\text { Biaya overhead } \\
\text { pabrik : }\end{array}$ & \\
\hline $\begin{array}{l}\text { Biaya tenaga } \\
\text { kerja tak } \\
\text { langsung }\end{array}$ & 74.840 .000 \\
\hline $\begin{array}{l}\text { Biaya bahan } \\
\text { penolong }\end{array}$ & 77.796 .650 \\
\hline $\begin{array}{l}\text { Biaya } \\
\text { penyusutan } \\
\text { mesin }\end{array}$ & 39.650 .000 \\
\hline $\begin{array}{l}\text { Biaya } \\
\text { penyusutan } \\
\text { gedung pabrik }\end{array}$ & 28.350 .000 \\
\hline $\begin{array}{l}\text { Biaya reparasi } \\
\text { dan } \\
\text { pemeliharaan }\end{array}$ & 7.111 .400 \\
\hline Biaya listrik & 5.398 .650 \\
\hline Biaya asuransi & 1.229 .193 .500 \\
\hline Total & \\
\hline
\end{tabular}

Sumber : Perusahaan diolah, 2018

\section{PEMBAHASAN}

\subsection{Interpretasi Hasil Penelitian}

Setelah dilakukan analisis data terhadap data yang ada, kemudian akan dibandingkan antara hasil penelitian yang sudah dilaksanakan dengan keadaan yang ada pada prusahaan sebagai berikut :

1. Perusahaan kurang dapat
menggunakan waktu produksi
dengan efisien, karena banyak
menggunakan aktivitas yang

tidakbernilai tambah. Hal ini ditunjukan dengan besarnya non valueadded time yang terdiridari atas set up time, move time, waiting time, dan inspection time dalam throughput timenya. MCE dari sistem produksi sekarang 83,4\%, berarti masih terdapat $16,6 \%(100 \%$ - 83,4\%) atau 23.331 menit non value added time didalam throughput time.

2. Ada beberapa masalah yang menyebabkan non value added time yaitu (a) Lay out mesin yang kurang baik sehingga menimbulkan move time dan waiting time. (b) Melakukan penyetelan dan persiapan mesin yang cukup lama sehingga menimbulkan set up time. (c) Masih memberikan toleransi pada produk yang rusak selama dalam proses produksi, sehingga menimbulkan move time dan juga waiting time (d) Memproduksi dalam jumlah yang besar sehingga menimbulkan move time dan juga waiting time.

3. Karena adanya non value added time menyebabkan turunnya waktu proses (process time ). Waktu proses hanya $83,4 \%$ dari throughput timenya, sehingga dalam 
Volume 4 Nomor 1, April 2018

menyelesaikan produksinya

perusahaan menggunakan waktu

lembur.Konsekuensinya waktu

produksi menjadi lebih panjang.

Semakin lama waktu produksi, maka semakin banyak biaya yang dikeluarkan untuk membuat produk tersebut. Biaya tersebut antara lain upah lembur tenaga kerja dan biaya listrik untuk mengoperasikan mesin karena adanya lembur.

4. Hubungan Just In Time dengan non value added activity. Ada beberapa hal utau kondisi yang mendukung diterapkanya Just In Time production pada Perusahaan.

Tabel 5

Rekapitulasi Harga Pokok Produksi , Harga Pokok Penjualan, Laba Perusahaan sebelum JIT dan sesudah JIT (dalam rupiah)

\begin{tabular}{|l|l|l|l|}
\hline \multicolumn{1}{|c|}{ Uraian } & \multicolumn{1}{|c|}{ Sebelum JIT } & Sesudah JIT & \multicolumn{1}{c|}{ Varian } \\
\hline Harga Pokok Produksi & 1.227 .486 .500 & 1.159 .048 .744 & 68.437 .756 \\
Harga Pokok Penjualan & 1.223 .306 .500 & 1.154 .868 .744 & 68.437 .756 \\
Laba Perusahaan & 286.903 .130 & 332.943 .447 & 46.040 .317 \\
\hline
\end{tabular}

Data diolah, 2018

Penurunan biaya tenaga kerja langsung, tenaga kerja tak langsung dan listrik akan berpengaruh pada total biaya produksi yang dikeluarkan perusahaan. Hal ini dapat dilihat pada tabel 5 yang menunjukan bahwa setelah penerapan sistem JIT Production, total biay produksi yang dikeluarkan sebesar Rp.1.156.616.494,00. Bila di bandingklan dengan pengeluaran biaya produksi yang sebelum penerapn sistem JIT Production yaitu Rp. 1.229.193.500,00, maka terjadi penghematan biaya produksi sebesar Rp. 72.577.006,00.
Manfaat yang dari keberhasilan dalam menekan atau mengefisiensikan biaya produksi yaitu pada laporan harga pokok penjualan mengalami penghematan sebesar Rp. 68.437.756,00. Angka tersebut diperoleh dari perbandingan harga pokok pejualan sebelum penerapan sistem JIT Production Rp. 1.223.306.500,00 dengan harg pokok penjualan setelah penerapan sistem JIT Production (tabel 11) Rp.1.154.868.744,00.

Dengan ditekannya harga pokok penjualan, diharapkan perusahaan dapat menekan harga jual produk, dengan 
tujuan untuk menambah daya saing produk dipasar dan laba yang dihasilkan perusahaan akan mengalami peningkatan. Hal ini dapat dilihat sebelum penerapan sisitem JIT Production laba yang diperoleh perusahaan sebesar Rp. 286.903.130,00 dan setelah perusahaan menerapkan sistem JIT Production laba perusahaan mengalami peningkatan yaitu sebesar Rp. 33.943.447,00.

\section{KESIMPULAN}

1. Penurunan biaya tenaga kerja langsung, tenaga kerja tak langsung dan listrik akan berpengaruh pada total biaya produksi yang dikeluarkan perusahaan. Hal ini dapat dilihat pada tabel 5 yang menunjukan bahwa setelah penerapan sistem JIT Production , total biay produksi yang dikeluarkan sebesar Rp.1.156.616.494,00. Bila di bandingklan dengan pengeluaran biaya produksi yang sebelum penerapn sistem JIT Production yaitu Rp. 1.229.193.500,00, maka terjadi penghematan biaya produksi sebesar Rp. 72.577.006,00.

2. Manfaat yang dari keberhasilan dalam menekan atau mengefisiensikan biaya produksi yaitu pada laporan harga pokok penjualan mengalami penghematan sebesar Rp. 68.437.756,00. Angka tersebut diperoleh dari perbandingan harga pokok pejualan sebelum penerapan sistem JIT Production Rp. 1.223.306.500,00 dengan harg pokok penjualan setelah penerapan sistem JIT Production (tabel 11) Rp.1.154.868.744,00.

3. Dengan ditekannya harga pokok penjualan, diharapkan perusahaan dapat menekan harga jual produk, dengan tujuan untuk menambah daya saing produk dipasar dan laba yang dihasilkan perusahaan akan mengalami peningkatan. Hal ini dapat dilihat sebelum penerapan sisitem JIT Production laba yang diperoleh perusahaan sebesar Rp. 286.903.130,00 dan setelah perusahaan menerapkan sistem JIT Production laba perusahaan mengalami peningkatan yaitu sebesar Rp. 33.943.447,00. 


\section{DAFTAR PUSTAKA}

Hidayat T,Jann, Teknologi Manufaktur Maju dan Implikasinya pada sistem Akuntansi Biaya, Manajemen dan Usahawan, No. 11 th xxi November 1992.

Horngren, Charles, $\mathrm{T}$ Foster George. Datar Srikanto M, (1994), Akuntansi Biaya Dengan Pendekatan Manajerial, Buku 1 dan 2, terjemahan, : Endah Susilaningtyas, Salemba Empat Prentice Hall , Jakarta

Hutchins, David, (1997), Just In Time , Terjemahan : Anton Adiwiyoto, Profesional Books , PO. BOX 331 , CPA 15418, Jakarta.

Imaai, Masaaki (1998), Gemba Kaizen, pendekatan akal Sehat, Berbiaya Rendah pada Manajemen, terjemahan: Kristanto Jahya,PT. Pustaka Binaman Pressindo, Jakarta

Menemukan

Pemborosan

Terselubung, Manajemen Dan Usahawan Indonesia No.01 Th xxv Januari 1996.

Mulyadi, (1993), Akuntansi

Manajemen : Konsep , Manfaat dan Rekayasa, STIE YKPN, Yogyakarta.

Ohno Taiichi, (1995) Just In Time Dalam Sistem Produksi Toyota, PT. Pustaka Binaman Pressindo, Jakarta

Santoso , Kristanto,Total Quality Management di Indonesia, Manajemen dan Usahawan Indonesia , No. 11 th $\mathrm{xxi}$ November 1992

Supriyono, (1994) Akuntansi Biaya dan Akuntasni Manajemen Untuk Teknologi Maju dan Globalisasi, Edisi Pertama , BPFE, Yogyakarta.

Tjiptono , Fandy dan Diana , Anastasia (1996) , Total Quality
Manajemen, Edisi 2, Ando Offset,Yogyakarta

Tunggal , A Wijaya (1991), Akuntansi Manajemen Kontemporer, Penerbit Rineka Cipta ,Jakarta. Wheatley, Malcolm (1992), Memahami

Teknik Tepat Waktu yang Sukses Dalam Sepekan , Terjemahan :Sugeng Panut,cetakan ke dua, Kesaint Blanc Indah Corp, Jakarta , 1995. 